\title{
MECHANISM OF FORMATION OF RADIALLY-GROWN MELTPATTERNS ON THE SURFACE OF ICE
}

by

AKIO TOUKaIRIN

Hokkaido University of Education, Kushiro Branch, Shiroyama 1-15-55, Kushiro, Hokkaido, Japan 085

\section{ABSTRACT}

Patterns like brittle-stars, known as "radially-grown meltpatterns" are formed on the surface of ice from water gushing through a hole in thin snow-covered ice. This in turn melts the snow on the surface while extending outward along the water veins produced.

This study has successfully produced artificial meltpatterns and thus made possible the accurate clarification of the mechanics of formation. Incidentally, concentric circle meltpatterns were also found. Matters concerning artificial meltpattern simulation tests and the formation speed are also discussed in this paper.

\section{OBSERVATIONS}

Water veins of radially-grown meltpatterns become transparent as snow melts and therefore appear black or blue. The snow piling in the vicinity of the water veins turns a whitish grey when soaked with water. Therefore, the contrast of black and whitish grey is immediately obvious and the "brittle-star" shaped radially grown meltpatterns can easily be seen. It is impressive to see tens of thousands of these patterns, with diameters ranging from a mere $5 \mathrm{~cm}$ to as large as $30 \mathrm{~m}$, scattered like stars over the ice.

When the ice on a lake is thin and covered with a thin layer of snow, a large number of small meltpatterns are formed. As the ice thickens and the layers of snow deepen, the smaller sized meltpatterns diminish in number but increase in size. Thus, the lake surface appears to be divided into cells like tortoise-shells (Figure 1). Holes in the snow-covered ice through which water gushed to form the meltpatterns, develop along three-grained intersections in the crystal grain boundaries (Toukairin 1979) or veins.

Conventional explanations of the mechanics of the formation of meltpatterns include various assumptions in addition to the above mentioned factors: for example, "they are formed as waterways for the water inflow of melted snow or rain" or "they are formed in the course of the in/out-flow of the lake water through a hole formed in the ice because of the vibration of the ice plate under the influence of wind" (Toukairin 1973). Since I have successfully produced artificial meltpatterns (Toukairin 1975,1977 ) it has become possible to clarify more accurately the mechanics of their formation.

Meltpatterns quite similar to those naturally produced can be formed by pouring water at about $0.5^{\circ} \mathrm{C}-6^{\circ} \mathrm{C}$ with a hose onto a point on the surface of fresh snow on a frozen lake. I found that these meltpatterns could be formed even in the laboratory by pouring water at the proper temperature on frost which was collected from the surface of pipes in a low temperature chamber and piled on an ice plate.

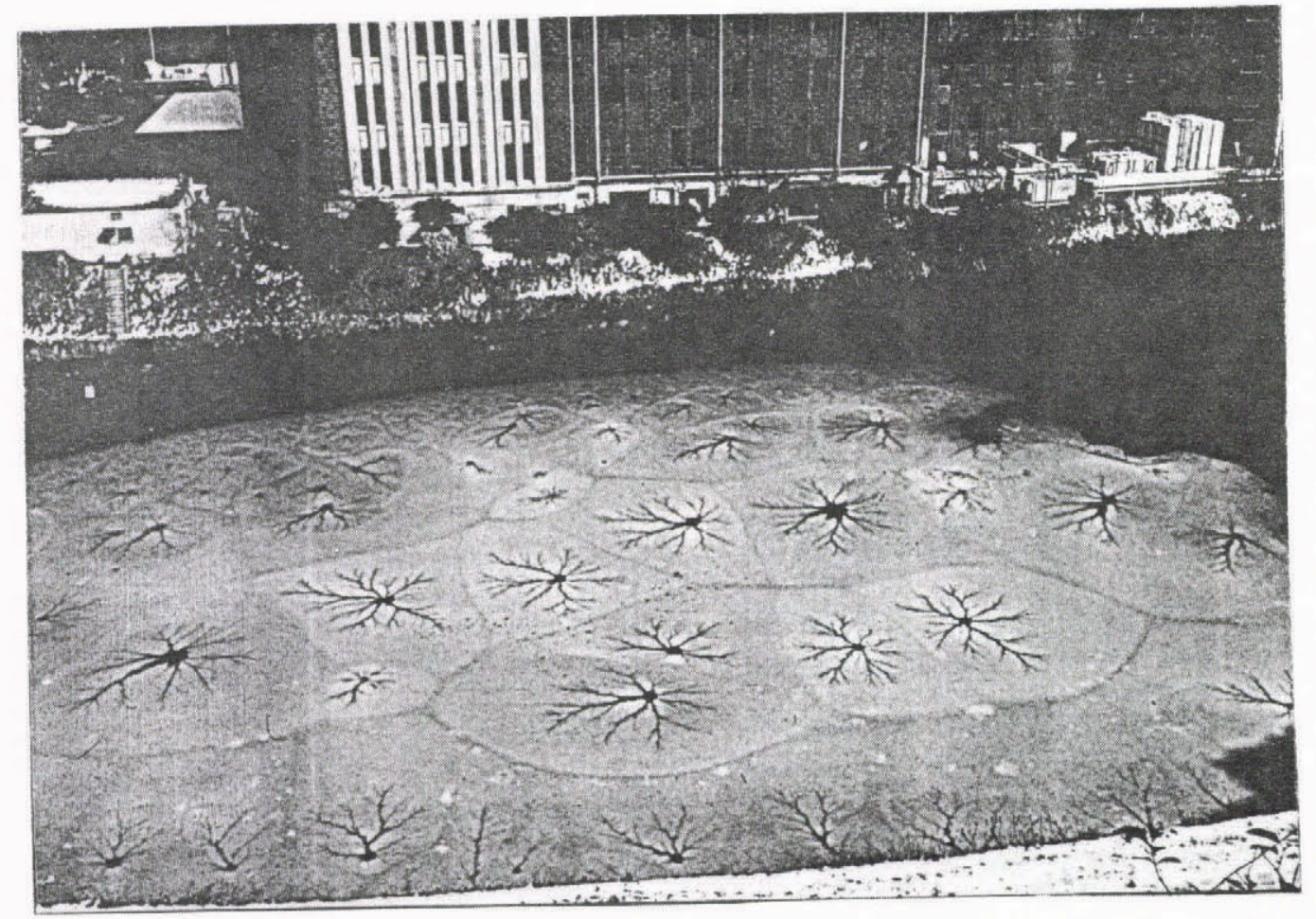

Fig.1. Radially-grown melt patterns of brittle-stars on the surface of ice in Ushigafuti pond on 2 February 1984 (by Tutomu Okazaki, in Kitanomaru Park, Tokyo, Japan). 


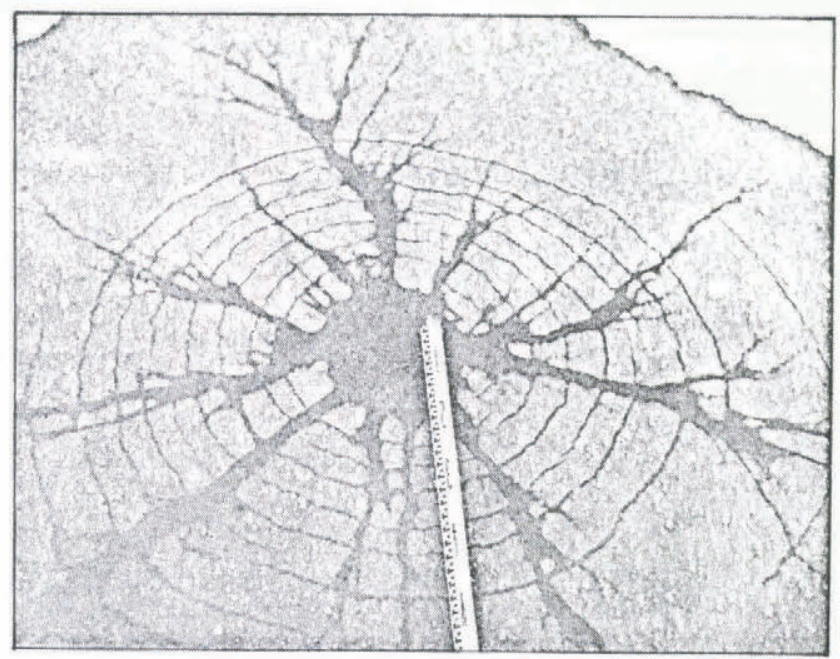

Fig.2. Concentric artificially simulated meltpatterns.

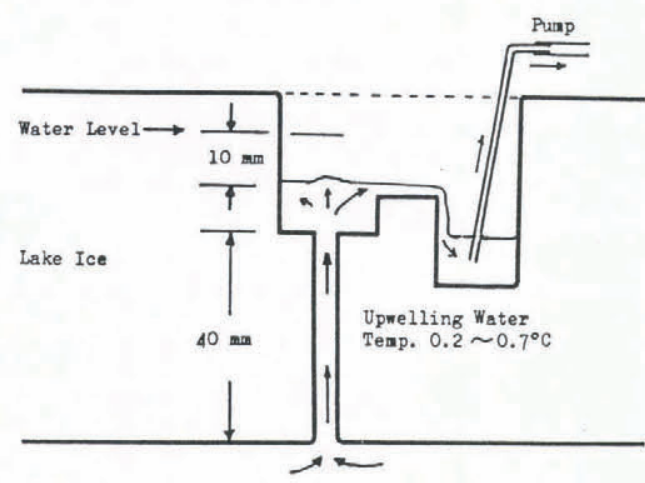

Lake Water

Fig.3. Typical view of test examining water gushing through a hole in the lake ice performed 30 March 1984, on the frozen surface of Lake Kussharo $\left(46^{\circ} \mathrm{N}, 144^{\circ} \mathrm{E}\right)$.

Brittle-star shaped meltpatterns thus formed are called "radially-grown meltpatterns" on the surface of ice.

Concentric circle meltpatterns (Figure 2) were first recognized in 1973. Artificial simulation of these patterns was also found to be possible. These patterns, which are radial patterns accompanied by concentric circles, are formed due to the partial collapse of the snow-plate under its own weight after the absorption of water by snow. It was experimentally confirmed that many such collapses take place at regular intervals.

Water poured onto a point on the snowcover on the ice plate extends outward, producing circular cracks on the surface of snowcover. This then leads to circular collapses. Many collapses take place as the water spreads further. The concentric cracks formed by these collapses accompany radial patterns, to form what is called "concentric circle patterns".

A small vertical hole opened through the lake ice becomes larger in diameter by the gushing of lake water at a higher temperature through the hole. This in turn increases the gushing speed. Figure 4 and Equation 1 show the relation between the amount of gushing water $Q$ (litre) and time $t$ (min) when gushing lake water under a pressure of $10 \mathrm{~mm} \mathrm{H}_{2} \mathrm{O}$ passed through a $1 \mathrm{~mm}$ dia. hole opened in lake ice $4 \mathrm{~cm}$ thick.

$$
\mathrm{Q}=120 \mathrm{e}^{0.067 \mathrm{t}}
$$

Based upon the above, an equation describing the relationship between meltpatterns growing speed and time is derived. If we have a snow fall on the $4 \mathrm{~cm}$ thick ice on the lake, and water keeps gushing through a hole, under pressure of snow weight, as described by

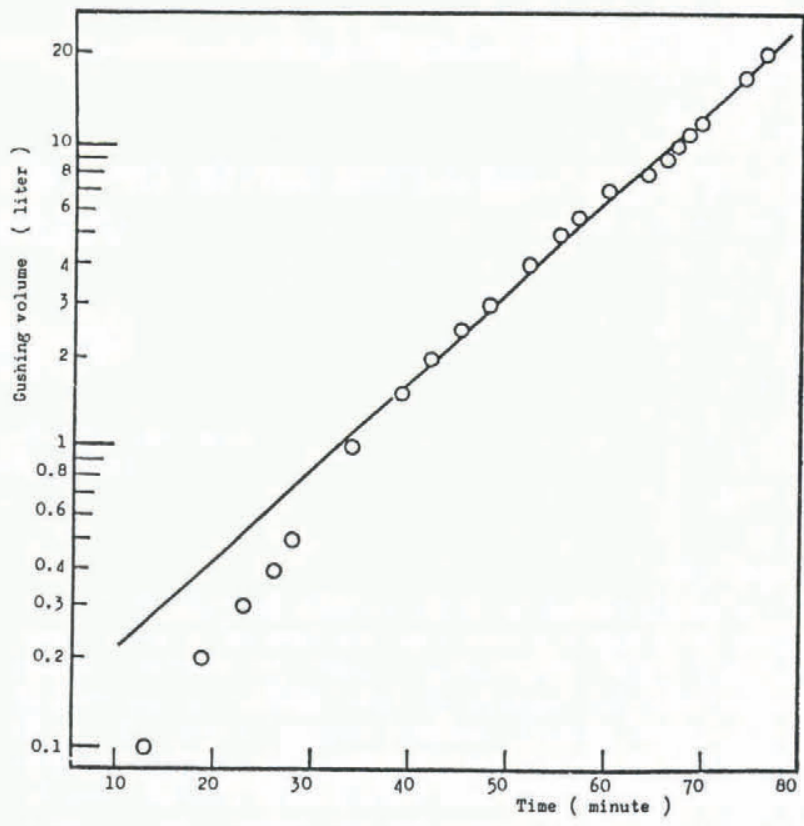

Fig.4. Relation between gushing volume and time.

Equation 1; and if the gushing water extends outward with the thickness of $\mathrm{H}$, the relation between the diameter of meltpatterns $\mathrm{D}$ and time $t$ can be given by the following equation:

$$
\mathrm{D}=\sqrt{\frac{480}{\pi \mathrm{H}}} \mathrm{e}^{0.0335 \mathrm{t}}
$$

This equation, however, holds true only under limited conditions, namely when snow lies on the frozen lake and water continues gushing as described by Equation 1.

\section{REFERENCES}

Toukairin A 1973 Study on the Radial Pattern of Ice Surface. Journal of the Japanese Society of Snow and Ice 35(4): 173-179

Toukairin A 1975 Saiensu. [Scientific American (Japanese edition)] Tokyo, Nihon Keizai Sinbunsya 5(2):

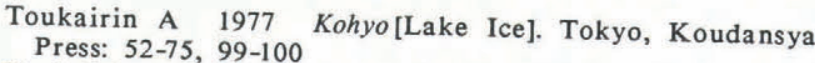

Toukairin A 1979 Development of water veins along the three-grain intersection in fresh water ice at the melting point. Journal of the Japanese Society of Snow and Ice 41(2): 121-130 